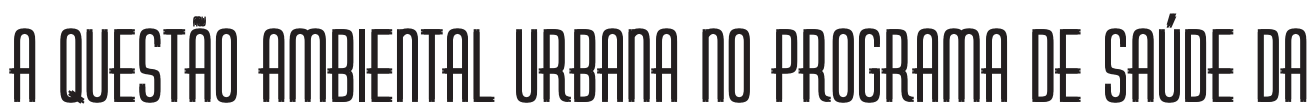

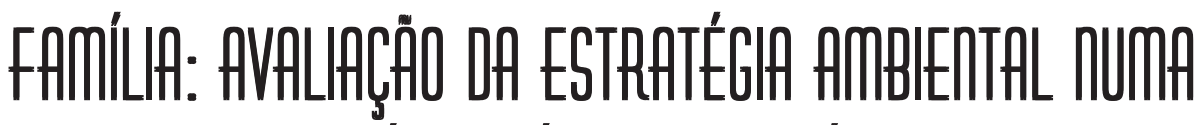 POLITCCH PÚBLLLCH DE SAUUOEE
}

\author{
AUREA MARIA ZÖLLNER IANNI* \\ LUIZ ANTONIO DIAS QUITÉRIO**
}

\section{METRÓPOLE, SAÚDE E AMBIENTE}

O tema ambiental nas metrópoles emerge da intersecção entre questões que decorrem dos problemas ambientais mais gerais das cidades e daqueles decorrentes das configurações urbanas enquanto formas particulares de organização social. No primeiro grupo enquadram-se, mais diretamente, as características associadas à posição e localização geográfica: o clima, a topografia, etc. No segundo grupo, enquadram-se as características e aspectos intra-urbanos das configurações das cidades no complexo metropolitano. Isto faz com que as cidades, como ambientes construídos, requalifiquem problemas elementares, como a domesticação da natureza, ao mesmo tempo em que introduzem novas e complexas questões.

\begin{abstract}
"A fragilidade de conhecimento de que se dispõe sobre o processo de estruturação interna das cidades e do nexo de articulações (ou determinações) estabelecidas entre as múltiplas e variadas manifestações da 'vida urbana' torna quimérica ou leviana qualquer tentativa de se calcular e arbitrar a distribuição de penalidades entre atores supostamente envolvidos, direta ou indiretamente, em projetos 'ecologicamente sustentáveis"' (SMOLKA, 1993: 143).
\end{abstract}

Na Saúde, a questão ambiental é marcada pela já conhecida relação entre a saúde e a provisão de água em quantidade e qualidade apropriadas e seu respectivo destino pós-utilização (esgotamento). Esta questão moveu, e ainda hoje move, o setor na direção das chamadas práticas sanitárias que, sistematizadas,

\footnotetext{
* Instituto de Saúde SES-SP e CEDEC.

** CEDEC e Centro de Vigilância Sanitária Ses SP.
} 
conformaram a tradicional área de Saneamento do Meio. Também tradicional são as atividades de vigilância e combate aos vetores em seus principais criadouros e nichos ecológicos, pontos vulneráveis de precária urbanização. Desta forma, o Sistema Único de Saúde (SUS) encontrou um espaço de atuação consolidando suas ações no âmbito da Vigilância Sanitária.

O mesmo não ocorreu em relação à poluição do ar (contaminação e ruído) ou do solo (por produtos perigosos) ou, ainda, no tocante a outros impactos ambientais com conseqüências diretas na saúde das populações. Portanto, trata-se de entender, para além do saneamento do meio, quais fatores e tendências ambientais estão em jogo, para que se possa definir medidas preventivas e corretivas possíveis, e o modelo que permite visualizar o papel do setor saúde nesse cenário é preconizado pela promoção da saúde.

É no documento "Novas Perspectivas para a Saúde dos Canadenses", divulgado em maio de 1974 pelo então Ministro da Saúde do Canadá, M. Lalonde, que o termo surgiu como um novo paradigma em saúde. O Informe parte do conceito de campo da saúde, decompondo-o em biologia humana, estilo de vida, organização da atenção à saúde e ambiente. Conclui que a organização da atenção concentra os maiores gastos diretos, enquanto os restantes (biologia humana, estilo de vida e ambiente) albergam o grosso dos determinantes da saúde. Cinco estratégias foram, então, propostas pelo Informe para abordar os problemas do campo da saúde: promoção da saúde, regulação, eficiência da atenção à saúde, pesquisa e estabelecimento de objetivos. O Informe Lalonde teve grande repercussão, a ponto de influenciar a I Conferência Internacional sobre Cuidados Primários de Saúde, convocada pela Organização Mundial de Saúde (OMS) em 1978 na cidade de Alma-Ata.

A Conferência de Ottawa, ocorrida em 1986, estabeleceu como estratégia fundamental para a promoção da saúde o entendimento de que a Saúde se realiza num contexto de múltiplos fatores, atores e interesses, sendo vista menos como um compartimento da administração pública e mais como um pressuposto na formulação de políticas, planos, programas e projetos. A Carta de Ottawa parte dessa estratégia para viabilizar cinco campos centrais de ação, dentre eles a criação de ambientes favoráveis à saúde. Neste ponto aparece, de modo inequívoco, que a proteção do ambiente e a conservação dos recursos naturais devem ocupar tempo e recursos do setor saúde. Reconhece, de um lado, o papel desses determinantes na conquista de ambientes favoráveis à saúde das populações e, de outro, a complexidade das sociedades nas quais se inserem e a interdependência entre os diversos setores (BUSS, 1998).

Disso depreende-se que a saúde se realiza, em larga medida, fora do setor saúde, em áreas/setores das atividades humanas nem sempre alcançáveis pelos mecanismos e estratégias tradicionais de prevenção e regulação. A promoção da saúde propõe que intervenções e diagnósticos devem emergir de processos que pressuponham interdisciplinaridade e inter-setorialidade. 


\title{
O PROGRAMA DE SAÚDE DA FAMÍLIA E A QUESTÃO AMBIENTAL
}

É recente a incorporação, pela Organização Mundial da Saúde (OMS), da problemática ambiental à atenção básica. O projeto de Atenção Primária Ambiental (APA), de 1998, é um primeiro esforço nesse sentido, tendo sido elaborado por sua representação na América Latina, a Organização Pan-Americana de Saúde (OPAS). Ainda incipiente, esta diretiva revela a urgência do enfrentamento intersetorial e interdisciplinar das questões de saúde e ambiente, presentes no cotidiano das populações e na dinâmica dos serviços e sistemas de saúde.

\begin{abstract}
"A Carta Pan-Americana sobre Saúde e Desenvolvimento Humano Sustentável, acordada na Conferência Pan-Americana sobre Saúde e Ambiente no Desenvolvimento Humano Sustentável (COPASADHS), realizada em Washington, D.C., em 1995, ao fixar os princípios de política e estratégia, estabelece que: 'a participação dos indivíduos e das comunidades para manter e melhorar seus ambientes de vida deve ser promovida e apoiada. A participação comunitária deve basear-se em estratégias para o desenvolvimento sustentável incluindo a atenção primária do ambiente, a atenção primária à saúde e a educação das crianças e adultos (grifo nosso). Em cada nível da organização social e política devem-se estimular e apoiar redes de interesses e pessoas que atuem em colaboração, a fim de fomentar a integração de preocupações e recursos setoriais nos processos de desenvolvimento' (ORGANIZAÇÃO PANAMERICANA DA SAÚDE, 2000)."
\end{abstract}

No entanto, a construção desse campo de saberes e de práticas é, ainda, incipiente, carecendo tanto de aprofundamento teórico quanto de ampliação do escopo dos conhecimentos pois, trata-se, em muitos casos, de problemas essencialmente novos. É o caso, por exemplo, das mudanças climáticas globais e os inúmeros desdobramentos para a saúde das populações daí decorrentes. Nesse sentido, torna-se necessário construir um sólido arcabouço que permita contribuir para a formulação de políticas públicas e a redefinição das práticas dos sistemas e serviços em saúde e ambiente nas cidades.

O Programa de Saúde Família (PSF) é apresentado como estratégia para a reversão do modelo assistencial vigente centrado na cura de doenças e no hospital. A complexidade de um quadro nosológico, no qual doenças relacionadas aos estilos de vida e ao meio ambiente adquirem crescente importância, justificaria um novo olhar do setor saúde sobre a população, cuja sistematização, do ponto de vista físico e social, permitiria propor intervenções para além das práticas curativas e preventivas, aproximando-se da promoção da saúde.

O PSF é um 'modelo de atenção' estruturado na ação localizada e, conseqüentemente, as formas de condução e gerência das ações são, também, localizadas, o que significa que toda a estratégia do Programa encontra-se assentada nas Equipes de Saúde da Família. Este modelo parece sugerir que o conjunto do trabalho das equipes resultaria, necessariamente, num sistema - de atenção básica de saúde. 
Esta configuração mostra-se, entretanto, insatisfatória quando inserida em contexto metropolitano que requer o enfretamento da atenção básica de forma articulada às várias esferas administrativas e das políticas públicas, intersetorialmente conectada e alicerçada em instrumental técnico, científico, gerencial, econômico-financeiro, de recursos humanos, etc. etc., mais sofisticados (AZEVEDO E GUIA, 2004).

No que se refere à temática ambiental, as áreas urbanas metropolitanas representam realidades sócio-ambientais diversas, articulando-se num mesmo território, com especificidades próprias, porém com determinações de ordem geral. Não há como se manter no limite singular da Equipe de Saúde da Família. Ela recebe, ininterruptamente, os impactos de determinantes globais. Esta tensão aparece na rotina de trabalho das equipes, é intrínseca à constituição do PSF e é a partir dela que se problematiza a inserção da temática ambiental nesse programa de atenção básica.

Se a questão ambiental é pouco trabalhada pelas Equipes de Saúde da Família, essa deficiência encontra suas bases na própria concepção de ambiente que o Programa tem e que estão expressas nas Normas e Diretrizes, segundo a Portaria 1866/ 97 do Ministério da Saúde. O PSF, analisado a partir desse documento, parece não incorporar uma concepção mais interativa das relações homem/ambiente/condições de saúde enquanto totalidade complexa e interveniente. Está distante, portanto, daquela presente no conceito de campo da saúde e de promoção da saúde.

Outro fator que contribui para a exigüidade da discussão ambiental no seio do PSF é o fato de que a análise de políticas ambientais no nível local é bastante recente. Segundo Ferreira (1998, p. 33), "parece incrível que uma metrópole como São Paulo, que concentra 10\% da população do país, não tenha realizado um diagnóstico geral de suas condições ambientais".

\section{A PESQUISA}

Com o objetivo de desenvolver metodologia e indicadores para avaliação permanente da implantação e impactos do PSF em Região Metropolitana, a pesquisa foi desenvolvida nos municípios de São Paulo, Santo André, São Bernardo do Campo e Diadema e procurou verificar de que maneira essa modalidade de atenção primária, trabalha as ações integradas em âmbito dos sistemas locais de saúde.

A questão que se coloca é verificar como a atenção básica, em nível local, atua sobre os efeitos e causas do processo saúde-doença da população, diante das intensas e constantes interferências e impactos da dinâmica ambiental local e regional.

Em virtude do caráter inovador do PSF e da inclusão, pioneira, da temática ambiental e de promoção da saúde num programa de atenção básica, a pesquisa assumiu, necessariamente, um caráter exploratório, descritivo.

A seleção dos casos foi feita por sorteio de Unidades de Saúde da Família (USF) nos municípios estudados. Para São Paulo, foram agrupados os Distritos Administrativos em seis estratos sociais, com base no Mapa da Exclusão (2000), tendo sido sorteados três Distritos e, dentro deles, a USF a ser pesquisada. Para os outros 
municípios, em virtude da dimensão geográfica e populacional, houve sorteio de uma USF em cada um deles. A partir dessa seleção, as Unidades pesquisadas ficaram assim estabelecidas:

São Paulo: USF Rio Claro, situada no Distrito Administrativo Parque São Rafael, zona leste do município; USF Vila Praia, situada no Distrito Administrativo Vila Andrade, zona sudoeste do município e; Centro Saúde Escola Barra Funda, situado no Distrito Administrativo Barra Funda, zona central do município. Santo André: USF Jardim Ana Maria. São Bernardo do Campo: USF Santa Cruz. Diadema: USF Promissão.

A observação 'sistemática e crítica' foi adotada como instrumento básico da pesquisa. Tratou-se de perceber o rotineiro, o usual, aquilo que a maioria deixa passar desapercebido por ter se tornado habitual (NOGUEIRA, 1968). Esta técnica, por valorizar os aspectos da vida social, do cotidiano, foi adequada aos objetivos da pesquisa na medida em que se pretendeu captar a tensão, o conflito e/ou dicotomias entre os princípios enunciados no Programa e a prática concreta das Equipes de Saúde da Família (ESF).

Por tratar-se de uma técnica que também permite identificar comportamentos não intencionais (ALVES-MAZZOTTI \& GEWANDSZNAJDER,1998), a observação é adequada para identificar se, no contato direto com a população e com a realidade local, a ESF supera a proposição difusa da questão ambiental contida no Programa, e se (ou até que ponto) essa prática se redefine e transforma.

Foram, também, realizadas entrevistas em grupo com roteiro semiestruturado, junto às equipes selecionadas com o objetivo de aprofundar o conteúdo observado, bem como o trabalho de campo foi precedido de análise de dados secundários sobre os municípios alvo.

\section{RESULTADOS}

Os resultados apontam a diversidade de temas e categorias, a complexidade intrínseca a cada um deles e a vastidão de um campo de conhecimento excessivamente interdisciplinar - a tomar o próprio campo da Saúde Pública/Coletiva, em si mesmo interdisciplinar, associado nesta pesquisa às áreas de meio ambiente e ocupação urbana, também interdisciplinares. Essa vastidão de questões reafirma como necessário o caráter descritivo da pesquisa, pois ela informa temas e problemas a serem posteriormente aprofundados.

\section{Ocupação Urbana e Moradia}

Com o olhar focalizado na saúde humana, as ESF interpretam os diferentes cenários urbanos delineados em cada uma das áreas estudadas, atribuindo-lhes maior ou menor parcela de responsabilidade na ocorrência de agravos e doenças. 
Há relatos sobre passeios públicos íngremes associados a quedas e traumas em favelas urbanizadas, áreas livres para lazer e caminhadas em bairros planejados, vielas estreitas que impedem o atendimento de urgências em áreas invadidas e a poeira das ruas sem pavimentação, a que atribuem a persistência de problemas respiratórios.

No tocante ao ambiente intra-domiciliar, são freqüentes as observações sobre falta de ventilação e umidade excessiva e a ocorrência de bronquites em adultos e crianças; escadas e acessos inseguros e o risco de acidentes domésticos; além da proximidade de córregos e barrancos e o permanente perigo de enchentes e deslizamentos.

A questão, portanto, parece estar menos relacionada à existência ou não da percepção dos Agentes Comunitários de Saúde (ACS) acerca das relações entre ocupação urbana e moradia, qualidade de vida e saúde, e mais às possibilidades de intervenção do PSF a serem implementadas a partir dessa percepção.

Entretanto, a despeito da percepção dos ACS identificada neste estudo, o instrumento de coleta e registro de informações referentes à situação da moradia no Sistema de Informação da Atenção Básica (SIAB) resume-se ao item "tipo de casa", com oito alternativas, sendo seis relativas ao material de construção e as demais sobre o número de cômodos e energia elétrica. Tamanho zelo em colher dados sobre material de construção da moradia tem justificativa epidemiológica: ao diferenciar a casa de tijolo / adobe, taipa revestida e taipa não-revestida, pretende-se, na verdade, inferir sobre a exposição dos seus moradores ao risco da doença de Chagas. Sabe-se que taipa não-revestida facilita a domiciliação do vetor da doença (barbeiro). São precisamente inferências similares que o SIAB não permite que sejam feitas em relação a alguns agravos associados a outras características das moradias, paradoxalmente percebidas pelos ACS, e que não encontram espaço para registro. As doenças associadas à ocupação urbana e à moradia têm etiologia mais complexa, e os seus controles escapam à estrita governabilidade do SUS, necessitando interlocução com as áreas de habitação e planejamento urbano, por exemplo.

\section{Saneamento Ambiental Urbano}

Considerando que em torno de dois terços das áreas estudadas coexistem micro-áreas providas e não providas de saneamento, e que algumas vezes essa diferença se dá no interior de uma mesma micro-área, considera-se que a maioria dos ACS já tenha vivenciado situações envolvendo algum problema de saneamento ambiental.

Explicitamente citado na Portaria 1886/97 em termos de um "levantamento das condições de saneamento básico" no âmbito "do mapeamento da área de abrangência dos ACS" (item 8.15.5), o tema é abordado com algum detalhamento no Sistema de Informações da Atenção Básica (SIAB), quadro "Situação da Moradia e Saneamento".

$\mathrm{O}$ que se verificou na pesquisa é que a complexidade das situações reais extrapola a capacidade de registro do SIAB. Há o exemplo do lixo. Quase todos os ACS se referem à existência de coleta, mas esta não é diária, ocorre em horários 
incompatíveis com a rotina da população e não percorre todas as ruas da micro área (em muitos casos porque não são largas ou planas o suficiente para circulação dos caminhões). Não há espaço para o registro dessas informações. Sendo assim, um relatório extraído do SIAB não seria adequado para ilustrar a situação de fato do saneamento existente nas áreas estudadas e mais, tenderia, em alguns casos, a minimizar a exposição da população a riscos.

Além do sistema de informação fazer vistas grossas a um problema clássico para a saúde pública, os ACS que chamam para o PSF a tarefa de reivindicar, organizar ou disciplinar essa questão o fazem sob intensas dificuldades.

Os sistemas de limpeza urbana no Brasil, e aqueles da Região Metropolitana de São Paulo em particular, não dispõem de experiência nem estrutura operacional para estender a coleta para áreas de urbanização irregular. Isso demanda, entre outras coisas, modificações no porte e modelo dos veículos coletores e nos horários de coleta, adequando-os às peculiaridades dessas áreas.

Percebe-se que os ACS, como representantes do governo e, portanto, atores fundamentais de uma política pública, não merecem nenhum tratamento diferenciado por parte do órgão público responsável.

Esta dinâmica estende-se também para as questões do abastecimento de água e coleta de esgotos. Não existem relatos de interrupção ou intermitência de abastecimento, nem aquelas relativas à qualidade da água, embora, pela localização das áreas e até por estarem na Região Metropolitana de São Paulo, é praticamente impossível que isso não ocorra, ainda que esporadicamente, em determinadas épocas do ano. Nesse aspecto o SIAB, ao não abrir espaço para este tipo de informação, ajuda a mascarar uma realidade preocupante em termos de saúde pública.

Nas áreas onde o abastecimento é feito através de soluções alternativas (poços freáticos, minas ou ligações clandestinas, 'gatos', na rede pública de abastecimento), foram citados laudos de análises laboratoriais confirmando contaminação da água, mas a solução para esses problemas passa por uma articulação inter-institucional que não está colocada como atribuição do PSF.

Tão visível quanto o lixo, e bem mais desagradável aos sentidos, o esgotamento sanitário aparece como problema em vários relatos; e problema para 'alguém resolver'. Em apenas uma área a solução - implantação de rede coletora em área invadida -, surgiu em decorrência de pressões da ESF. Nas demais, os relatos acompanham a generalidade das fichas do SIAB, inclusive com os ACS designando erroneamente por "fossa" a uma parte interna da rede coletora (a caixa de passagem nos domicílios). Noutro caso, a descrição "esgoto a céu aberto" era, na verdade, o lançamento de águas servidas provenientes da pia da cozinha e da lavagem de roupas.

\section{Risco Químico}

Poucas situações caracterizam melhor uma área metropolitana brasileira que o crescimento desordenado, ignorando áreas potencialmente perigosas para o assentamento humano, expondo milhares de pessoas a riscos de morte, seja por doenças, 
seja em razão de acidentes. A exposição de populações a determinados riscos químicos ou a acidentes químicos ambientais ampliados, vem ocupando crescentemente o setor saúde que, mais uma vez, obriga-se a interagir com setores historicamente distantes como os de energia e transporte.

Entre as áreas estudadas, três delas apresentam situações que oferecem riscos químicos a seus moradores.

A primeira é a micro área contígua a um duto da Petrobrás. Os ACS não souberam precisar a natureza do fluido (gás, óleo ou ambos), mas acompanharam um trabalho subvencionado pela empresa juntamente com uma ONG. O objetivo seria remover a população da área de risco, potencializado, no caso, pela concomitância do duto com uma rede de transmissão de energia (torres de alta tensão). Depois de várias reuniões comunitárias com a Petrobrás, das quais participaram os ACS, a única providência concreta foi a cessão, pela empresa, de uma área para construir uma lixeira. Com isso, a coleta passou a ocorrer duas vezes por semana.

A segunda, menos explícita, mas igualmente preocupante, é de um conjunto habitacional construído há vinte anos sobre um aterro sanitário desativado. Apesar da produção de gás inflamável aparentemente estar encerrada, persistem incertezas sobre a presença de outros gases, cujo perigo não é a explosividade, mas a carcinogenicidade. Os ACS desta ESF descrevem situações de doenças relacionadas às características da área - notadamente doenças de pele em crianças e em cães como fatos do passado. Atualmente, segundo eles, não há nada de anormal.

A terceira situação não tem a contigüidade das anteriores, mas o agente químico, por ser um gás, dependendo das condições de dispersão, pode atingir a população residente na área e manter-se em concentrações elevadas por longos períodos, ampliando a exposição. Trata-se de um bairro localizado na área de abrangência do Pólo Petroquímico de Capuava, a uma distância de aproximadamente um quilômetro. A despeito do perigo intrínseco à atividade, o risco, aludido no relato de pesquisa, refere-se á poluição do ar por gases emitidos dos "flares" (queimadores localizados no alto das torres), sobre os quais existem suspeitas de provocarem alterações no funcionamento da tireóide.

De comum, os três casos têm a total insciência do PSF como instância do SUS que pretende reordenar o modelo assistencial a partir do território.

No caso da micro-área contígua a um duto da Petrobrás, os ACS participaram de uma ação na acepção mais simbólica da palavra. Não tiveram voz, não se diferenciaram, não decidiram. No caso da área sobre o aterro desativado e naquela sob influência das emissões atmosféricas do Pólo Petroquímico, não há nem mesmo a curiosidade científica em investigar a prevalência de certos agravos, o que seria obrigatório no segundo caso, já que a gerência do programa é de uma instituição de ensino superior.

Por certo essas iniciativas não seriam dos ACS, mas da coordenação do programa, se esta tivesse outras preocupações acerca da saúde da população adscrita que não aquelas minimizadas pelo SIAB que, por sinal, não tem espaço para o registro de informações aqui expostas. 


\section{Criação de Animais}

Há relatos que se referem à criação de animais no histórico das áreas estudadas, apontando a urbanização - com a redução do tamanho dos lotes e a própria modificação dos hábitos -, como fatores responsáveis pelo desaparecimento da prática de criadouros.

Entretanto, persistem relatos atuais de criações, ocorrendo em áreas que ainda preservam costumes rurais, embora estejam incrustadas em regiões intensamente urbanizadas. Apesar de não serem associadas de imediato a doenças, a criação de animais chega aos ACS em função do incômodo provocado pelas fezes.

Embora a lei proíba esse tipo de prática em área urbana, o ACS não dispõe dos meios necessários para coibi-la. Por outro lado, a criação de animais de pequeno porte, como galinhas, representa, na maioria dos casos, considerável aporte nutricional na dieta das pessoas com baixo poder aquisitivo. Já os cavalos, também referidos, servem de tração para charretes e carroças que recolhem material inservível para reciclagem.

Outra referência é a criação de animais domésticos, como gatos e cachorros, em domicílios muito pequenos, sem ventilação, de modo que esses animais convivem no mesmo espaço exíguo em que as pessoas. Numa dessas situações, a moradora queixou-se para o ACS que sua bronquite não melhorava. Ela residia com um filho deficiente físico num pequeno barraco construído em área invadida, junto com oito gatos e um hamster. Há relatos de cães com sarna e outras doenças potencialmente transmissíveis ao homem e até a sugestão de incorporar um veterinário à equipe.

Outra variante foi encontrada numa favela urbanizada. Ali o pesquisador estranhou a quantidade de casas com gaiolas e pássaros, descobrindo, na seqüência, tratar-se de comércio ilegal de aves, crime ambiental passível de multa e prisão. Os ACS sabem disso, mas não denunciam, temendo represálias dos traficantes.

Nos dois casos, deparam-se os ACS, e por extensão o PSF, com situaçõeslimite. Uma possível saída para esse impasse seria, uma vez mais, compartilhar esses problemas com o conjunto de instituições públicas e privadas que de alguma forma tenham afinidade com este problema, de onde emergem os fatores de risco. Isso exigiria, também uma vez mais, que o PSF definisse e implementasse métodos e procedimentos capazes de articular os setores da sociedade identificados com os problemas levantados, cuja 'solução-produto' poderia denominar-se Saúde.

\section{Força de Trabalho: o PSF por fora dos domicílios}

A reestruturação produtiva, largamente discutida na década de 1990, provocou conseqüências diretas no mundo do trabalho e nas condições de vida das populações. É quase consenso que tais mudanças trouxeram a precarização do trabalho nas formas de contratação, nas modalidades de ocupação, na emergência de segmentos até então inexistentes no mercado de trabalho, na exclusão de outros. Este fenômeno, 
evidente em áreas urbanas, não poderia, como se pôde verificar na pesquisa, passar desapercebido pelas equipes de PSF.

e lixo.

Há, sempre, uma estreita relação entre precarização do trabalho, pobreza

Um dos exemplos dessa relação é o relato dos trabalhadores imigrantes clandestinos (paraguaios, bolivianos, peruanos), trabalhando em pequenas indústrias insalubres de micro-empresários também clandestinos (coreanos, chineses). Uma amostra da dinâmica econômica e demográfica global, onde se articulam mão-deobra barata, clandestinidade, sonegação fiscal, alta produtividade, péssimas condições sanitárias e exclusão social.

Outro exemplo da relação acima aparece na relação trabalho/lixo. Há, cada vez mais, segmentos da população que encontram no lixo sua viabilidade de sobrevivência. No entanto, as equipes de PSF que trabalham com populações inseridas neste tipo de atividade produtiva, reclamam que as áreas onde residem dificilmente ficam limpas, criando condições para o desenvolvimento de doenças. O desafio é tão grande que, segundo ACS, há casos de moradores de rua que, sobreviventes do lixo, rejeitam até mesmo a comida oferecida em alojamentos (fator fundamental para a manutenção da saúde), já que conseguem alimento no próprio 'rico' lixo urbano.

Mais uma vez, os profissionais de Saúde da Família, sensíveis às condições concretas de vida e saúde da população, encontram dificuldades, dentro desse modelo de atenção, em conduzir problema tão novo e complexo no qual articulam-se mundo do trabalho, exclusão social e urbanização.

\section{Questões Pontuais - Problemas Gerais}

Há problemas ambientais com implicações na saúde das populações e nas práticas das ESF que, mesmo aparecendo de forma isolada numa ou noutra Unidade pesquisada, indicam a emergência de questões de âmbito mais geral e que poderiam vir, rapidamente, a assumir uma dimensão regional no PSF da área metropolitana de São Paulo. Eles encontram ressonância direta, e de forma evidente, a máxima ambientalista "pensar global, agir local".

\section{Preservar o Manancial}

Apenas uma das Unidades pesquisadas localiza-se em área de proteção aos mananciais, em São Bernardo do Campo, município contíguo à represa Billings, que abastece parte dos municípios da região metropolitana.

Nessa área, os ACS têm clareza sobre a necessidade de preservação, o que faz com que haja, por parte dos mesmos, a incorporação dessa problemática no trabalho desenvolvido cotidianamente, tanto em relação ao saneamento principalmente no que se refere à destinação adequada dos dejetos (a área não tem rede instalada), quanto em relação ao desmatamento (obediência aos limites legais para preservação do solo). 
A tensão, aí, aparece entre os ACS e os outros membros da equipe (médicos e enfermeiros) que permanecem na Unidade. Reféns da atenção clínica e da normatividade dos procedimentos preconizados para suas competências no seio da ESF, esses profissionais atendem apenas aos problemas médico-clínicos que lhes são atribuídos previamente, como diabetes, hipertensão, pré-natal, etc, desconsiderando a voz dos agentes e o contexto real no qual insere-se a população daquela área de abrangência.

Nesse sentido, os determinantes que uma configuração sócio-ambiental como esta provoca nas condições de vida da população e, conseqüentemente, em suas condições de saúde são, invariavelmente, trabalhados pela equipe sob forte tensão de práticas e saberes. De um lado, os profissionais mais especializados e de formação universitária do Programa, obedecendo a um modelo clínico de atenção, de outro, os ACS, membros da comunidade, enfrentando, concretamente, essa realidade, a partir de seu patrimônio de saber construído local e socialmente.

\section{Poluição do Ar}

Sabe-se que este é um dos principais problemas ambientais de regiões intensamente urbanizadas e com larga comprovação científica dos agravos da poluição atmosférica à saúde humana ${ }^{1}$. Dados epidemiológicos vêm confirmando a estreita relação entre doenças respiratórias e poluição atmosférica e/ou mudanças climáticas. Entretanto, este fator ambiental não é objeto de notificação pelo SIAB, talvez pelo fato de que o ar não seja um bem que se mantenha dentro das fronteiras da área de abrangência da ESF, do domicílio ou da família. Como enfrentar doenças que assumem, necessariamente, dimensão epidemiológica (em populações, coletividades), com uma estratégia essencialmente clínica, ambulatorial, dirigida ao indivíduo? Como atuar sobre problemas que se encontram dispersos nos marcos de um espaço não apenas cartográfico, mas territorial, as áreas de abrangência?

Há referências sobre poluição do ar em dois dos casos estudados.

$\mathrm{Na}$ Unidade localizada no centro de São Paulo, onde se atribui a poluição a uma Usina de asfalto, ainda em atividade, à presença de muitas funilarias além do tráfego intenso de veículos. A ESF, além de atender os casos e participar de um projeto de pesquisa sobre a questão, encaminhou, junto com a população, um abaixo-assinado à administração regional para que fossem interrompidas as atividades da Usina. Este fato revela a dificuldade da equipe em fazer-se ouvir e contemplar numa ação que, necessariamente, extrapola os âmbitos do PSF e do próprio setor saúde. Curioso observar que a dificuldade de articulação intersetorial revela-se, também, intra-setorialmente; não há referências sobre a convocação da Vigilância Sanitária para intervir no problema.

mesmo ocorre em Santo André onde, se atribui a contaminação do ar ao Pólo Petroquímico. O paradoxo é que, a despeito de ser uma Unidade gerenciada por instituição acadêmica, há total ausência de ação intersetorial, de pesquisa, acompanhamento e providências em relação ao problema: 


\section{COMENTÁRIO}

A complexidade das realidades locais, distritais, municipais, metropolitanas, onde se ajustam e conflitam problemas sócio-ambientais e de saúde tão distintos, como a ausência de saneamento básico e risco químico, cidadãos e clandestinos, sobreviventes do trabalho e do lixo, etc, coloca a clássica estratégia excessivamente normativa da Saúde em cheque. Essa realidade leva a Saúde a se repensar e repensar os avanços necessários ao SUS, numa lógica, agora, mais radicalmente intersetorial, democrática e inclusiva.

\section{REFERÊNCIAS BIBLIOGRÁFICAS}

ALVES-MAZZOTTI, A.J. \& GEWANDSNAJDER, F. O Método nas Ciências Sociais: pesquisa quantitativa e qualitativa. Editora Pioneira. São Paulo. 1998.

AZEVEDO, S. \& GUIA, V. R. M. "Os Dilemas Institucionais da Gestão Metropolitana no Brasil” In RIBEIRO, L.C. (Org) Metrópoles. Entre a Coesão e a Fragmentação, a Cooperação e o Conflito. FASE/Ed. Fundação Perseu Abramo/Observatório das Metrópoles. 2004

BUSS, P.M. (org.) Promoção da saúde e a saúde pública - contribuição para o debate entre as escolas de saúde pública da América Latina. Rio, julho de 1998 (versão preliminar distribuída pela Secretaria de Políticas de Saúde do Ministério da Saúde).

CAMPBELL, T. "Desenvolvimento Urbano no Terceiro Mundo: Dilemas Ambientais e Pobres Urbanos" In LEONARD, H. J. (org) Meio Ambiente e Pobreza. Estratégias de Desenvolvimento para uma Agenda Comum. Jorge Zahar Editor. 1992.

DECRETO 12.342/78, 27/Setembro/1978. Código Sanitário do Estado de São Paulo.

DRAPER, R, Perspectives on Health Promotion. Canadian Public Health Association, 1995. FERREIRA, L.C. A Questão Ambiental. Sustentabilidade e Políticas Públicas no Brasil. Editora Boitempo. São Paulo. 1998.

FRANCO, T. \& MEHRY, E. "PSF: contradições e novos desafios". Conferência Nacional de Saúde on Line. www.datasus.gov.br/cns. 2002

FRENCH, H. "Sharing the Air" In: FRENCH, H. Vanishing Borders - Protecting the Planet in the Age of Globalization. WW Norton \& Company. New York-London 2000.

HARTZ, Z.M. A. "Pesquisa em Avaliação da Atenção Básica: a necessária complementação do monitoramento" Divulgação em Saúde para Debate. N. 21.29:35. Rio de Janeiro. 2000.

NOGUEIRA, O. Pesquisa Social. Companhia Editora Nacional/Universidade de São Paulo. São Paulo. 1968.

SAMPAIO, M.R.A. \& PEREIRA, P.C.X. "Habitação em São Paulo". Estudos Avançados. Vol. 17, N. 48. 167:183. São Paulo. Maio/Agosto 2003.

SHAEFER, M. Salud, médio ambiente y desarollo: enfoques para la preparación de estrategias a nivel de paises para el bienestar humano, según la Agende 21. Washington. OPS, 1994. 
AUREA MARIA ZÖLLNER IANNI

LUIZ ANTONIO DIAS QUITÉRIO

\title{
A QUESTÃO AMBIENTAL URBANA NO PROGRAMA DE SAÚDE DA FAMÍLIA: AVALIAÇÃO DA ESTRATÉGIA AMBIENTAL NUMA POLÍTICA PÚBLICA DE SAÚDE
}

\begin{abstract}
Resumo
Este artigo apresenta resultados da pesquisa realizada, em 2003/04, na Região Metropolitana de São Paulo - municípios de São Paulo, Santo André, São Bernardo do Campo e Diadema - sobre as relações entre atenção básica em saúde e meio ambiente. Avaliou-se o Programa de Saúde Família, uma política estratégica do Ministério da Saúde/Brasil, que visa a reversão do modelo assistencial vigente, contemplando a complexidade do quadro nosológico atual em que doenças relacionadas aos estilos de vida e ao meio ambiente adquirem crescente importância. O conceito de Promoção da Saúde, incorporado ao Programa, propõe a viabilização de ambientes favoráveis à saúde, entendendo que a Saúde se realiza na confluência de múltiplos fatores, atores e interesses; sendo vista, menos como um compartimento da administração pública, mais como um pressuposto na formulação de políticas, planos, programas e projetos. Neste ponto aparece, de modo inequívoco, que a proteção do ambiente e a conservação dos recursos naturais devem ocupar tempo e recursos do setor. O caráter inovador da temática levou a um estudo de modelagem sócioantropológica, que permitiu identificar os principais problemas e aspectos da conexão saúde/ambiente na esfera do cotidiano das populações envolvidas e nas práticas dos profissionais da saúde.
\end{abstract}

Palavras-chave: Saúde, Ambiente, Metrópole, Políticas Públicas

\section{"URBAN ENVIRONMENTAL ASPECTS ON FAMILY HEALTH PROGRAM: EVALUATING THE ENVIRONMENTAL STRATEGY OF A HEALTH PUBLIC POLICY"}

\begin{abstract}
This paper is focused on the relation between health basic care and environment and how it is considered on the Family Health Program (PSF), an strategic policy of Ministry of Health/Brazil wich aims the revertion of usual health policies, strongly based on medical and health tecnologies resources and failing to avoid the incresase of incidence and prevalence of diseases due to environmental issues and way of living. Health Promotion concept is added to this program in order to make
\end{abstract}


true the construction of kindly health environments, as health is more than a part of public administration, but the effect of public policies, plans, programs and projects proposed and executed by government agencies. On this point of view, environmental protection and nature resources conservation have to be considered as an important issue by health promotion program as PSF. In order to evaluate how PSF is implemented in four cities of São Paulo metropolitan area (São Paulo, Santo André, São Bernardo do Campo e Diadema), a socio-antopological approach was adopted, wich allowed identify the main aspects of health/environment links in dayly activities of community and health professionals.

Keywords: Health, Environment, Metropolis, Public Policies 